\title{
The Effects of Pandemic on Construction Industry in the UK
}

\author{
Abdussalam Shibani \\ School of Energy, \\ Construction and Environment, \\ Coventry University, \\ CV 15 FB, Coventry, United Kingdom \\ Dyaa Hassan \\ Researcher School of Energy, \\ Construction and Environment, \\ Coventry University, \\ $C V_{1}$ FB, Coventry, United Kingdom

\section{Nehal Shakir} \\ MSc. Student, School of Energy, \\ Construction and Environment, \\ Coventry University, \\ $C V_{1}$ FB, Coventry, United Kingdom
}

DOI: https://doi.org/10.36941/mjss-2020-0o63

\section{Abstract}

Pandemics such as: Covid-19 virus have a major impact on the economy of the world and the construction industry has not been exempted. This research investigates the effects of pandemic on construction industry in the UK, and particularly, ways in which the UK construction industry stakeholders such as project managers, contractors, engineers and subcontractors have responded to these pandemics. The research involved a 30 study participants who comprised site engineers, project managers, construction teams, subcontractors and contractors. The findings reported construction companies both dealing with residential and commercial development were major affected by Covid-19 pandemic due to lockdown and social distancing in construction sites. The strategy that was applied by construction companies was maintaining a good relationship with their suppliers and the safety of construction teams. The findings of the research will offer construction companies in the UK insights on how to deal with such pandemics in future to become more resilient.

Keywords: Pandemic, Construction Industry, UK

\section{Introduction}

The financial crisis that followed the subprime mortgage market in the United States in 2008 very quickly spread across the world with disastrous repercussion for many countries and many people. Indeed, the most severely hit industries both internationally and in the United Kingdom was the 
construction industry with many jobs being lost and several firms shutting down (Edmund, Yang, and Eric, 2018). According to Supriadi, and Pheng (2018) these events happens all over sudden or a lengthy process. For instance, process-based predicaments normally send timely warning signs, therefore, construction forms that can catch up with these signs in preparation of the impending crises. Accordingly, the most significant developments in regard to crisis control is to develop a timely warning system (Simard, and Laberge, 2018). In this sense, Halou et al., (2019) argue that if a building firm approximates a crisis well and implement crisis management in an efficient manner they are likely to overcome the crises with little or zero damage. Therefore, it is important that construction companies learn how to manage crisis concepts to run away from crises. The effects of the 2008 recession greatly impacted all aspects of the national economy in the UK. The most considerable declined has been experienced in house building with commercial and civil engineering sub-sectors falling. As a result, this situation led to the Bank of England cutting its interest rate. The decline in the housing construction has also slumped the house marketing. For instance, statistics has shown that house prices fell by nearly $16 \%$ in 2008.

With the coming of the Covid-19 pandemic, the message across the UK has been clear that all people should stay at home. Indeed, this has posed a major dilemma to the construction sector since a majority of the people cannot work from home. However, that means that most of the workers in this industry will not get paid if they do not show up for work hence losing their jobs (Laing, 2020). The construction activity in the UK has rapidly declined since the financial crisis in March 2020 whereby thousands of builders work has been halted in addition to job cuts due to coronavirus hitting the economy. Recent reports have shown that the UK's construction IHS Mark it purchasing managers' index dropping from $52 \%$ to $39 \%$, which is the lowest reading for a period of more than ten years. Reports from the Department for business Enterprise and Regulatory Reform (BERR), it has revealed that the UK construction sector comprises more than 250000 companies, which employees over 2 million individuals. As a result, this contributes to approximately $8.5 \%$ of the nation's Gross Domestic Products (GDP). Helm, D. (2020) also pointed out that the total lockdown caused by COVID-19 has severely curtailed economic activities. The construction industry with no exception have been severely affected by the COVID-19 pandemic and there is no study exclusively reported as the date of April 2020 focusing on the impact of the pandemic on the construction industry hence this study is aimed to discover the effects.

The aim of the research is to determine the effects of the pandemic on construction industry in the UK, therefore, the research will utilize the following research objectives to determine the appropriate measures to recover the construction industry from the financial crisis, as well as find out the impact of financial crisis to the construction industry. This research explores the strategies that should be implemented by the construction organizations to ensure success, and find out practices that have been adopted by contraction contractors in response to the challenges presented by the global financial crisis.

\section{Methodology}

The researcher utilized two research methods to collect data that is quantitative and qualitative research. First method is quantitative research which is normally conducted to obtain views from a large number of individuals. The researcher used a descriptive research method in collecting data from the respondents (Shekhar et al., 2019). The first step of the quantitative research is determining sample. The most suitable approach of collecting data was found to be the use of online questionnaires. Second method is qualitative research methods entails gathering and analyzing data that is not numerical such as opinions, text, and videos to understand concepts (Huan-Niemiet al., 2016). This method is applied to obtain in-depth insights into a problem and establish novel research ideas. In regard to this context the researcher used in-depth interview method to collect findings about the research topic. The interviews were done by speaking to participants such as project managers, contractors, subcontractors and site engineers about the effects of pandemics on 
construction industry particularly the financial crisis and the current Covid-19 pandemic. On the same note, research design is described as a planned approach in regard to how a research is carried out (Etikan, Musa and Alkassim, 2016). The research study was on the effects of pandemic on construction industry in the UK whereby the following research objectives were formulated in response to the study to assess the appropriate measures to recover the construction industry from the financial crisis; to find out the impact of financial crisis to the construction industry; to explore the strategies that should be implemented by the construction organizations to ensure success and to find out practices that have been adopted by contraction contractors in response to the challenges presented by the global financial crisis.

The research method that was used to collect data was quantitative because it was found to be more relevant. Quantitative research design was used because it provided the researcher with the chance to use arithmetic making it possible to convert the received responses into figures during analysis of the findings to ensure that they align with standards of the experiment (Günbayi and Sorm, 2018).At the same time, descriptive research allows the researcher the chance to determine the view of the study respondents regarding the effects of the pandemic on the construction industry in the UK through the asked questionnaires and interview questions. The source of data for this study consisted data from different construction companies such as Interserve Plc, Keller Group Plc, Morgan Sindall and Amey UK Plc. Primary data collection method was the main approach used by the researcher to gathered data from the study. Due to the present health condition brought by the Covid-19 pandemic as well as the limited time for the research the researcher employed an online survey questionnaire to collect data and used video conferencing for conducting the interview questions.

\subsection{Population and Sampling Techniques}

Soni et al., (2019) define population as a set of events or objects which have similar characteristics and interests. Population in a research refers to a set of persons in possession of the same features. Therefore, a population is an expansive collection of persons that pays attention on scientific research. However, the expansiveness of the population makes it impossible for the researcher to use it since it could not be practical to test all people in the construction industry. As a result, the researcher applied a sampling technique to obtain an appropriate population that was used for the research. Sampling is a process that is utilized to choose study unit such as people or items within the population of interest with the goal of investigating the sample in a fairly general outcome (Etikan, Musa and Alkassim, 2016). A sample is a sub-group that is picked from a specified population that is taken as a representative of the entire populace. In this sense, the researcher employed a stratified random sampling approach because it gave all respondents equal possibility of being picked to take part in the research thus it helped to avoid biased representation of those who were selected to represent the whole population (Sharma, 2017). The sample size that was used by the researcher was 30 individuals who were picked in a random approach from the study population. The sample size was reached to base on a study by Roscoe (1995) which indicated that an appropriate sample size for any research should be a minimum of thirty and a maximum of five hundred respondents (Rahi, 2017). Therefore, a sample size of 30 respondents was found to be suitable because it lied within the recommended sample size.

\subsection{Framework and Data Analysis}

Data analysis is critical in ensuring that data is accurately gathered to make sure it provided findings that are reliable. In this context the researcher used a questionnaire and interview questions as the key research tool. The questionnaire was developed by using the research questions to aid in collection of information selected from the research variable. The research questionnaire was subdivided into three parts that part a) general information; b) ways to minimize the impact of the pandemic on construction 
and c) strategies used by construction companies in the face of pandemic. The first part evaluated the general information of the respondents such as gender, age group, level of education attained, work experience and job position. The second and third part of the questionnaire comprised questions related to diverse research variables linked to the effects of pandemic on construction industry in the UK and the strategies that have been put in place to counter this challenge. The questionnaire was established based on a five scale known as Likert scale comprising of the following interpretations 1-Strongly disagree, 2-disagree, 3-neutral, 4-agree and lastly 5-strongly agree.

\section{Results and Data Analysis}

The researcher presented the findings of the questionnaire and the interview. The total number of participants in this study was 30 . The participants comprised both male and female with different age groups, level of education, work experience and job positions. The objective of this study was to gather data and information in regards to the effects of pandemics on construction industry in the UK using closed-ended questions and a list of predetermined interview questions. The responses were measured using a Likert scale system, which comprised a scale of 1 to 5 whereby 1-represented strongly disagree, 2-disagree, 3-neutral, 4-agree and 5-strongly agree. The questionnaire consisted three parts as described in detail in the next part. The data was presented in form of frequency tables, descriptive statistical mean, standard deviations and charts.

This part comprised data analysis based on the questionnaire as well as the interview responses collected from the field research the topic under investigation. To be able to analyze the findings collected from the field, the researcher utilized frequency distribution tables as well as charts to display the data. On the same note, the researcher gave standard deviation and mean for every question contained in the questionnaire. The analysis involved 30 respondents for the questionnaire and five interviews for the interview questions. The analysis was conducted according to the structure of the questionnaire, hence it involved three parts for the questionnaire and then the interview.

Table 1. Frequency of respondents' gender

\begin{tabular}{llcccc}
\hline & & Frequency & Percent & Valid Percent & Cumulative Percent \\
\hline \multirow{4}{*}{ Valid } & Male & 20 & 66.7 & 66.7 & 66.7 \\
& Female & 10 & 33.3 & 33.3 & 100.0 \\
& Total & 30 & 100.0 & 100.0 & \\
\hline
\end{tabular}

The table above was used to present data displaying the genders of the respondents who took part in the research study. Based on the table, it was found that male respondents were 20 which was $66.7 \%$ of the total research population. For the females participants there were 10, representing $33.3 \%$ of the entire research population. In this regard, it was found that male respondents were more than females in the research study. The male respondents were more than their female counterparts in the research study. On the same note, the mean for the respondents who took part in the study was 1.33, which had a standard deviation of 0.179 .

Table 2. Frequency of respondents' age distribution

\begin{tabular}{llcccc}
\hline & Frequency & Percent & Valid Percent & Cumulative Percent \\
\hline \multirow{4}{*}{ Valid } & 25-30 Years & 8 & 26.7 & 26.7 & 26.7 \\
& 31-35 Years & 9 & 30.0 & 30.0 & 56.7 \\
& 36-40 & 6 & 20.0 & 20.0 & 76.7 \\
& $41-45$ Years & 4 & 13.3 & 13.3 & 90.0 \\
& Above 45 Years & 3 & 10.0 & 10.0 & 100.0 \\
& Total & 30 & 100.0 & 100.0 & \\
\hline
\end{tabular}


Based on the results from mentioned above table it illustrates the age distribution for the research students. The table indicates that 8 respondents fall in the age group between 25-30 years, which is $26.7 \%$ of the total study participants. 9 respondents fall in the age group between $31-35$ years representing $30 \%$ of the research population. 6 respondents fall in the age group between $36-40$ years, which is $20 \%$ of the whole study participants.4 respondents fall in the age group between $41^{-} 45$ years, which is $13.3 \%$ of the research population.3 respondents were from the age group above 45 years representing $10 \%$ of the whole research. The age group with the highest number of participants was that between $31-35$ years at $30 \%$, followed by that between $25-30$ years at $26.7 \%$. The age group with the least participants was that above 45 years at $10 \%$ of the entire study population. In accordance to the above table, it was found that most of the respondents to the study were of age group of 31-35 years and 25-30 years. On the other hand, the age group with the least number of respondents was those above 45 years.

Table 3. Frequency of respondents' level of education attained

\begin{tabular}{llcccc}
\hline & Frequency & Percent & Valid Percent & Cumulative Percent \\
\hline \multirow{4}{*}{ Valid } & High School & 5 & 16.7 & 16.7 & 16.7 \\
& Diploma & 10 & 33.3 & 33.3 & 50.0 \\
& Graduate & 10 & 33.3 & 33.3 & 83.3 \\
& Master & 3 & 10.0 & 10.0 & 93.3 \\
& PhD & 2 & 6.7 & 6.7 & 100.0 \\
& Total & 30 & 100.0 & 100.0 & \\
\hline
\end{tabular}

The above table shows different education levels of research participants involved in the research. The data shows that 5 respondents had High School level of education which is equivalent to $16.7 \%$ of the total study population. On the other hand, 10 respondents, which is $33.3 \%$ of the entire research population had Diploma level of education. Similarly, 10 respondents representing $33.3 \%$ of the research population were Graduates. However, participants with Master level of education were 3 which represents $10 \%$ of the whole research population. In addition to that, 2 participants, which is equivalent to $6.7 \%$ of the entire research population had $\mathrm{PhD}$ level of education. In this sense, it means that $66.6 \%$ of the research participants have Diploma and Graduate level of education, followed by those with High School education level at $16.7 \%$ while that with the least number of participants was those with $\mathrm{PhD}$ level of education at $6.7 \%$ of the whole study population. The results revealed that, most of the respondents had attained an education level of diploma and degree (graduate) while the least number of respondents had attained an education level of $\mathrm{PhD}$.

Table 4. Frequency of respondents' work experience

\begin{tabular}{llcccc}
\hline & Frequency & Percent & Valid Percent & Cumulative Percent \\
\hline \multirow{4}{*}{ Valid } & 1-3 Years & 8 & 26.7 & 26.7 & 26.7 \\
& 4-5 Years & 12 & 40.0 & 40.0 & 66.7 \\
& 6-8 Years & 4 & 13.3 & 13.3 & 80.0 \\
& Above 8 Years & 6 & 20.0 & 20.0 & 100.0 \\
Total & 30 & 100.0 & 100.0 & \\
\hline
\end{tabular}

The table above is a representation of data displaying the work experience of respondents who took part in the research study. In accordance with above data, it indicates that 8 participants which is equivalent to $26.7 \%$ fall in the age group between $1-3$ years. On the other hand, 12 respondents fall between the age group of 4-5 years, which is equivalent to $40 \%$ of the total population. 4 respondents were from age group between 6-8 years which is equal $13.3 \%$ of the whole population. Among the research participants, 6 respondents which is equal to $20 \%$ fall between the age group of above 8 
years of work experience. Based on the above data, majority of participants in the research fall between 4-5 years at $40 \%$, followed by age group $1-3$ years of work experience at $26.7 \%$. Participants with the least work experience fall between the age group 6-8 years, which is equal to $13.3 \%$ of the total population. The respondents who had the leading number in terms of working experience was 4-5 years followed by 1-3 years. The least respondents had a work experience of 5-8 years.

Table 5. Frequency of respondents' job position

\begin{tabular}{llcccc}
\hline & Frequency & Percent & Valid Percent & Cumulative Percent \\
\hline \multirow{6}{*}{ Valid } & 5 & 16.7 & 16.7 & 16.7 \\
& Subcontractor & 5 & 16.7 & 16.7 & 33.3 \\
Site Engineer & 3 & 10.0 & 10.0 & 43.3 \\
& Project Manager & 7 & 23.3 & 23.3 & 66.7 \\
Construction Team & 10 & 33.3 & 33.3 & 100.0 \\
Total & 30 & 100.0 & 100.0 & \\
\hline
\end{tabular}

The table above was used to present data displaying job position of the respondents who took part in the research study. The data indicate that 5 participants accounting for $16.7 \%$ of the whole research group were Contractors. Similarly, 5 respondents, which is equivalent to $16.7 \%$ of the research population also were Subcontractors. On the other hand, 3 participants which represents $10 \%$ of the entire study population were Site Engineer. On the same note, 7 respondents, representing $23.3 \%$ of the total study population were Project Manager. In addition, 10 respondents, which is equivalent to $33.3 \%$ of the whole study population, were in the Construction Team. Based on the provided responses it was found that 10 participants accounting for $33.4 \%$ of the total research population were Contractor and Subcontractors, followed by 10 participants representing $33.3 \%$ of the whole population while Site Engineer had the least number with 3 respondents accounting for $10 \%$ of the entire research population. Based on the results, the highest number of respondents in the research study held a job position of construction team, followed by project manager. The job position that had the least number of responses held the position of a site engineer.

Table 6. Responses regarding how the construction industry has provided worksite with health and safety rule signage

\begin{tabular}{llcccc}
\hline & Frequency & Percent & Valid Percent & Cumulative Percent \\
\hline \multirow{4}{*}{ Valid } & Disagree & 1 & $3 \cdot 3$ & 3.3 & 3.3 \\
& Neutral & 3 & 10.0 & 10.0 & 13.3 \\
& Agree & 15 & 50.0 & 50.0 & 63.3 \\
& Strongly Agree & 11 & 36.7 & 36.7 & 100.0 \\
& Total & 30 & 100.0 & 100.0 & \\
\hline
\end{tabular}

In regard to the question: the construction industry has provided the worksite with health and safety rule signage it was found that only one $(3.3 \%)$ of the entire number of respondents was in disagreement that the construction industry. On the same note, it was noted that $3(10 \%)$ of the total number of respondents were neutral to the asked question. On the other hand, it was found that 15 respondents which is $50 \%$ of the entire study population agreed that the construction industry has provided the worksite with health and safety rule signage. Similarly, 11 respondents which represented $36.7 \%$ of the total number of respondents strongly agreed to the asked research question. In summary, it was found that $86.7 \%$ of the total respondents to the study were in agreement that the construction industry provided their worksites with health and safety rule signage. Therefore, this means that the construction industry had taken precaution measures to ensure the safety of their construction labour force to curb Covid-19 in the construction industry. 
Table 7. Responses regarding how contractors have equipped their personnel with protective equipment when working

\begin{tabular}{llcccc}
\hline & Frequency & Percent & Valid Percent & Cumulative Percent \\
\hline \multirow{6}{*}{ Valid } & 1 & $3 \cdot 3$ & $3 \cdot 3$ & $3 \cdot 3$ \\
& Disagree & 2 & 6.7 & 6.7 & 10.0 \\
& Neutral & 4 & 13.3 & 13.3 & 23.3 \\
& Agree & 18 & 60.0 & 60.0 & 83.3 \\
& Strongly Agree & 5 & 16.7 & 16.7 & 100.0 \\
& Total & 30 & 100.0 & 100.0 & \\
\hline
\end{tabular}

In accordance to the question: contractors have equipped their personnel with protective equipment when working the following responses were recorded. From the responses received it was noted that 1 respondent which represented $3.3 \%$ of the total study population strongly disagreed that contractors did not equip their personnel with protective equipment when working, similarly 2 respondents which is $6.7 \%$ of the whole study population also disagreed. However, it was found that 4 respondents which represented $13.3 \%$ were neutral about the asked question. On the other hand, 18 respondents representing $60 \%$ of the entire research population agreed that the constrictors have provided their personnel with protective equipment while working. On the same note, it was found that 5 respondents representing $16.7 \%$ of the research population strongly agreed to that contractors have equipped their personnel with protective equipment while working. In general, the research found that $76.7 \%$ of the respondents to the study were in agreement that contractors in the construction industry have equipped their personnel with protective equipment while working to help fight against Covid-19.

Table 8. Response regarding all frequently touched surfaces and items cleaned and disinfected

\begin{tabular}{llcccc}
\hline & Frequency & Percent & Valid Percent & Cumulative Percent \\
\hline \multirow{4}{*}{ Valid } & Disagree & 2 & 6.7 & 6.7 & 6.7 \\
& Neutral & 3 & 10.0 & 10.0 & 16.7 \\
& Agree & 15 & 50.0 & 50.0 & 66.7 \\
& Strongly Agree & 10 & 33.3 & 33.3 & 100.0 \\
& Total & 30 & 100.0 & 100.0 & \\
\hline
\end{tabular}

In regard to the question: the contraction management keeps all frequently touched surfaces and items clean and disinfected, it was reported that 2 respondents, which represented $6.7 \%$ of the entire study population disagreed that the construction management do not ensure that frequently touched surfaces and items are cleaned and disinfected. Unfortunately, it was noted that 3 respondents representing $10 \%$ of the entire respondents to the study were neutral to the asked question. On the other hand, 15 respondents to the study which is $50 \%$ of the study population were in agreement that the construction management keeps all frequently touched surfaces and items clean and disinfected. On the same note, 10 respondents, which represented $33.3 \%$ of the study population were in strong agreement that the construction management keeps all frequently touched surfaces and items clean and disinfected. In summary it was found that $83.3 \%$ of the respondents who took part in the research study were in agreement of the asked question. 
Table 9. Response distribution regarding the question: Only one worker is inside a freight elevator at one time

\begin{tabular}{llllll}
\hline & Frequency & Percent & Valid Percent & Cumulative Percent \\
\hline \multirow{4}{*}{ Strongly Disagree } & 1 & $3 \cdot 3$ & 3.3 & 3.3 \\
Disagree & 2 & 6.7 & 6.7 & 10.0 \\
Neutral & 2 & 6.7 & 6.7 & 16.7 \\
& Agree & 15 & 50.0 & 50.0 & 66.7 \\
Strongly Agree & 10 & $33 \cdot 3$ & 33.3 & 100.0 \\
Total & 30 & 100.0 & 100.0 & \\
\hline
\end{tabular}

In regard to the question: only one worker is allowed inside a freight elevator at one time by construction companies, it was found that 1 respondent which represents $3.3 \%$ of the study population strongly disagreed with the question that not only one worker is allowed inside a fright elevator at one time by construction companies. Similarly, 2 respondents representing $6.7 \%$ of the total study population also disagreed with the asked question saying that not only one worker is allowed inside a freight elevator at one time by construction companies. It was also noted that 2 respondents representing $6.7 \%$ of the total study population were neutral to the asked question. On the other hand, 15 respondents, which accounted for $50 \%$ of the total number of respondents in the study were in agreement that only one worker is allowed inside a freight elevator at one time by construction companies. Similarly, 10 respondents which is $33.3 \%$ of the entire study population were in strong agreement about the asked question. In summary, the number of respondents who were in agreement with the above asked question was $83.3 \%$ while those were not in agreement was only $10 \%$. Therefore, this revealed that construction companies were only allowing one worker inside a freight elevator at one time in observation of Covid-19 measure to enhance safety of their work force.

Table 10. Response about how the construction has maintained a two-meter distance between workers

\begin{tabular}{llcccc}
\hline & Frequency & Percent & Valid Percent & Cumulative Percent \\
\hline \multirow{4}{*}{ Valid } & Disagree & 2 & 6.7 & 6.7 & 6.7 \\
& Neutral & 3 & 10.0 & 10.0 & 16.7 \\
& Agree & 15 & 50.0 & 50.0 & 66.7 \\
& Strongly Agree & 10 & 33.3 & 33.3 & 100.0 \\
& Total & 30 & 100.0 & 100.0 & \\
\hline
\end{tabular}

The table above presents responses on the question: the construction maintains a two-meter distance between workers. Based on the received responses it was found that 2 responses, accounting for $6.7 \%$ of the total number of responses to the study disagreed that construction companies did maintain a two-meter distance between workers. However, it was noted that 3 respondents $(10 \%)$ of the study population were neutral about the asked question. On the other hand, 15 respondents which represented $50 \%$ of the study population were in agreement that construction companies marinated a two-meter distance between workers. Similarly, 10 respondents, which accounted for $33.3 \%$ of the study populace were in strong agreement about the asked question. Accordingly, $83.3 \%$ of the respondents to the question were in agreements with the above asked question, which means that construction companies maintained a two-meter distance among workers to ensure safety of their workforce due to Covid-19. 
Table 11. Response regarding how project managers have installed extra hand washing stations in construction sites

\begin{tabular}{llcccc}
\hline & Frequency & Percent & Valid Percent & Cumulative Percent \\
\hline \multirow{6}{*}{ Valid } & Strongly Disagree & 1 & 3.3 & 3.3 & $3 \cdot 3$ \\
& Disagree & 3 & 10.0 & 10.0 & 13.3 \\
& Neutral & 2 & 6.7 & 6.7 & 20.0 \\
& Agree & 18 & 60.0 & 60.0 & 80.0 \\
& Strongly Agree & 6 & 20.0 & 20.0 & 100.0 \\
& Total & 30 & 100.0 & 100.0 & \\
\hline
\end{tabular}

The aforementioned table displays responses to the question: project managers have installed extra hand washing stations in construction sites. The following responses were received. It was found that 1 respondent which represented $3.3 \%$ of the total respondents to the study strongly disagreed to the asked question stating that project managers have not installed extra hand washing stations in construction sites. Similarly, 3 respondents which represented $10 \%$ of the total research population also disagreed about the asked question. It was also found that 2 respondents $(6.7 \%)$ of the study were neutral about the asked question. On the other hand, 18 respondents representing $60 \%$ of the entire study population were in agreement that project managers have installed extra hand washing stations in construction sites. On the same note, 6 respondents which is equivalent to $20 \%$ of the study populace were in strong agreement about the asked question.

Table 12. Response regarding how the construction company has reviewed its contract and service agreements for potential protection issues

\begin{tabular}{llcccc}
\hline & Frequency & Percent & Valid Percent & Cumulative Percent \\
\hline \multirow{4}{*}{ Valid } & Disagree & 1 & 3.3 & 3.3 & 3.3 \\
& Neutral & 2 & 6.7 & 6.7 & 10.0 \\
& Agree & 20 & 66.7 & 66.7 & 76.7 \\
& Strongly Agree & 7 & 23.3 & 23.3 & 100.0 \\
& Total & 30 & 100.0 & 100.0 & \\
\hline
\end{tabular}

In regard to the responses on the question: the construction company has reviewed its contract and service agreements for potential protection issues the following responses were reported. Based on the findings from the table above it was noted that 1 respondent, which represents $3.3 \%$ of the total number of respondents to the study was in disagreement that the construction company has not reviewed its contract and service agreements for potential protection issues. 2 respondents were found to be neutral about the asked question. 20 respondents representing $66.7 \%$ of the whole study population were in agreement that the construction company has reviewed its contract and service agreements for potential protection issues. Additionally, 7 respondents accounting for $23.3 \%$ of the study population were in strong agreement about the asked question. The response percentage in agreement about the asked question was $90 \%$ of the entire study population, which means construction companies had reviewed their contracts and service agreements for potential protection issues due to Covid-19 pandemic.

Table 13. Response regarding how construction firms have determined ideal projects that they are actively pursuing

\begin{tabular}{llcccc}
\hline & Frequency & Percent & Valid Percent & Cumulative Percent \\
\hline \multirow{4}{*}{ Valid } & Disagree & 1 & 3.3 & 3.3 & 3.3 \\
& Neutral & 4 & 13.3 & 13.3 & 16.7 \\
& Agree & 20 & 66.7 & 66.7 & 83.3 \\
& Strongly Agree & 5 & 16.7 & 16.7 & 100.0 \\
Total & 30 & 100.0 & 100.0 & \\
\hline
\end{tabular}


The table above displays responses regarding the question: the construction firm has determined ideal projects that they are actively pursuing. In this sense, it was found that 1 respondent accounting for $3.3 \%$ of the number of respondents were in disagreement that construction firms had not determined ideal projects that they are actively pursuing. 4 respondents which is equal to $13.3 \%$ of the entire study populace were neutral about the asked question. On the other hand, 20 respondents which accounts for $66.7 \%$ of the whole study population were in agreement that the construction firm has determined ideal projects that they are actively pursuing. Similarly, 5 respondents representing $16.7 \%$ of the research population strongly agreed to the asked question. In summary, $83.4 \%$ of the respondents who took part in the study were in agreement that construction firms had determined ideal project that they were actively pursuing.

Table 14. Responses regarding how construction companies have adjusted their schedule to avoid the slowdown bottleneck

\begin{tabular}{llcccc}
\hline & Frequency & Percent & Valid Percent & Cumulative Percent \\
\hline \multirow{4}{*}{ Valid } & Strongly Disagree & 1 & $3 \cdot 3$ & $3 \cdot 3$ & $3 \cdot 3$ \\
& Disagree & 3 & 10.0 & 10.0 & $13 \cdot 3$ \\
& Neutral & 1 & $3 \cdot 3$ & $3 \cdot 3$ & 16.7 \\
& Agree & 19 & $63 \cdot 3$ & 63.3 & 80.0 \\
& Strongly Agree & 6 & 20.0 & 20.0 & 100.0 \\
Total & 30 & 100.0 & 100.0 & \\
\hline
\end{tabular}

Based on the data presented in the table above regarding the question: the construction companies have adjusted their schedule to avoid the slowdown bottleneck, it was found that 1 respondents representing $3.3 \%$ of the study population strongly disagreed to the asked question arguing that construction companies had not adjusted their schedule to avoid slowdown bottleneck. Similarly, 3 respondents representing $10 \%$ of the study population were also in disagreement about the asked question. It was also found that 1 respondent representing $3.3 \%$ of the total study population was neutral about the matter. Nonetheless, 19 respondents representing $63.3 \%$ of the entire research population were in agreement that the construction companies have adjusted their schedule to avoid the slowdown bottleneck. On the same note, 6 respondents representing $20 \%$ were in strongly agreement about the asked question.

Table 15. Response regarding how construction companies have improved their office productivity and lowered overhead costs

\begin{tabular}{llcccc}
\hline & Frequency & Percent & Valid Percent & Cumulative Percent \\
\hline \multirow{4}{*}{ Valid } & Disagree & 2 & 6.7 & 6.7 & 6.7 \\
& Neutral & 2 & 6.7 & 6.7 & 13.3 \\
& Agree & 21 & 70.0 & 70.0 & 83.3 \\
& Strongly Agree & 5 & 16.7 & 16.7 & 100.0 \\
& Total & 30 & 100.0 & 100.0 & \\
\hline
\end{tabular}

The table above provided responses to the question: construction companies have improved their office productivity and lowered overhead costs. From the presented data it was found that 2 respondents $(6.7 \%)$ of the total population were in disagreements that construction companies have not improved their office productivity and lowered overhead costs. It was also noted that 2 respondents $(6.7 \%)$ of the total population were neutral about the asked question. 21 respondents representing $70 \%$ of the study population were in agreements that construction companies have improved their office productivity and lowered overhead costs. also, 5 respondents representing $16.7 \%$ of the study population were in strongly agreement about the asked question. 


\section{Analysis of the Interview}

The researcher interviewed two interviews a project manager and a manager for a construction company. Both interviews were working with construction companies that had specialized in developing residential homes and commercial apartments. For the first interview (project manager) it was fund that before Covid-19 being declared a pandemic the company was having three ongoing project. However, due to the pandemic one of the project had to stopped completely while two project continued but operated in an on and off manner. For the second interview (construction manager) it was reported that the company was working on a commercial project of twenty-one flats. The project was supposed to be completed by May but due to covid-19 the project had not been completed yet.

As a result of the pandemic construction companies adopted new strategies. Some of the strategies that had been undertaken included: creating a good relationship with the suppliers and working in shifts and breaks where workers would report to work for two or three days in a week.

For the external analysis it would help the construction companies to the major opportunities and treats facing the construction industry and plan adequately. The challenges that were faced by construction companies during the covid-19 pandemic include:

- Delay in the delivery of construction materials due to lockdown.

- Delay in completion of construction project due to lockdown and other safety measure.

- Social distance was found to be a major challenge.

The construction companies were reported to experience financial crisis in terms of losses and lack of access to money from banks and clients. However, despite the pandemic it was reported that construction companies did not have future strategies in preparation of a similar pandemic.

\section{Findings}

The essence of the survey questions and the interview was to explore the effects of pandemic particularly Covid-19 on construction industry in the UK. The researcher used both quantitative and qualitative research where the quantitative research involved a questionnaire while qualitative research involved an interview. The number of respondents to the research questionnaire was 30 and 2 interviews. The responses to the questionnaire was analyzed using SPSS software with the findings being represented using frequency tables, and charts. The findings from the interview were reported as provided by the interview based on the interview questions. In accordance to the recorded findings it was found that respondents to the questionnaire provided different responses to the asked survey questions on the research topic. The findings revealed that most of the respondents were in agreement with the asked research questions.

\section{Conclusions}

The research was conducted to determine the effects of pandemic on construction industry in the UK particularly, the 2008 recession and Covid-19 pandemic. The researcher used a survey questionnaire and interview to collect data from the study field. A majority of the respondents were in agreement with the asked survey questions. From the interview findings it was found that Covid-19 has significantly affected the construction industry hence resulting in many projects being stopped and others extending their deadline. As a result, construction companies have experienced a lot of losses since people are no longer spending on home constructions or commercial development. On the same note, the pandemic has led to construction companies facing financial constraints due to lack of money from clients and banks. Furthermore, the covid-19 pandemic has resulted in grounding of many projects due to lack of construction materials because of lockdown that made the supply of materials impossible. 


\section{References}

Babu, S.S. and Sudhakar, D.B., (2016). Construction project management during economic crisis. International Journal of Management, $7(7)$.

Carlson, E., (2018). Vigilant resilience: The possibilities for renewal through preparedness. Corporate Communications: An International Journal.

Edmund, B.T., Yang, H. and Eric, A., (2018). A General Overview of the Impact of Global Financial Crisis on Construction Industries. In ICCREM 2018: Analysis of Real Estate and the Construction Industry (pp. 28-38). Reston, VA: American Society of Civil Engineers.

Etikan, I., Musa, S. A., and Alkassim, R. S. (2016). Comparison of convenience sampling and purposive sampling. American journal of theoretical and applied statistics, 5(1), 1-4.

Faisal, A., Albrecht, J.N. and Coetzee, W.J., (2020). Renegotiating organisational crisis management in urban tourism: strategic imperatives of niche construction. International Journal of Tourism Cities.

Głodziński, E. and Marciniak, S., (2016). Organisational innovations in crisis management of project-based enterprises. Economics and Business, 28(1), pp.26-32.

Głodziński, E. and Marciniak, S., (2016). Organisational innovations in crisis management of project-based enterprises. Economics and Business, 28(1), pp.26-32.

Gulko, N., Hyde, C. and Seppala, N., (2017). Disclosure of corporate risks and governance before, during and after the global financial crisis: case study in the UK construction industry in 2006-2009. International Journal of Disclosure and Governance, 14(3), pp.207-223.

Günbayi, I. and Sorm, S., (2018). Social Paradigms in Guiding Social Research Design: The Functional, Interpretive, Radical Humanist and Radical Structural Paradigms. Online Submission, 9(2), pp.57-76. The Effects of Pandemic on Construction Industry in the UK 51.

Halou, M., Samin, R. and Ahmad, M., (2019). Impacts of change management on risk and cost management of a construction projects. Journal of Project Management, 4(2), pp.157-164.

Huan-Niemi, E., Rikkonen, P., Niemi, J., Wuori, O. and Niemi, J., (2016). Combining quantitative and qualitative research methods to foresee the changes in the Finnish agri-food sector. Futures, 83, pp.88-99.

Laing, T., (2020). The economic impact of the Coronavirus 2019 (Covid-2019): Implications for the mining industry. The Extractive Industries and Society.

Leavy, P., 2017. Research design: Quantitative, qualitative, mixed methods, arts-based, and community-based participatory research approaches. Guilford Publications.

Maloletko, A.N., Bikbulatova, A.A., Mkrttchian, V.S., Tolstykh, T.O., Vinogradova, M.V. and Kaurova, O.V., (2016). The digital model of the formation of human capital as part of the socioeconomic and spatial reactive projects. Contemporary Problems of Social Work, 2(4), pp.58-66.

Meng, X., 2020. Proactive management in the context of construction supply chains. Production Planning $\mathcal{E}$ Control, 31(7), pp.527-539.

Mhetre, K., Konnur, B.A. and Landage, A.B., (2016). Risk management in construction industry. Int. J. Eng. Res, 5, pp.153-155.

Mojtahedi, M. and Oo, B.L., (2017). Critical attributes for proactive engagement of stakeholders in disaster risk management. International Journal of Disaster Risk Reduction, 21, pp.35-43.

Patil, M.S.N., Desai, D.B. and Gupta, A.K., (2016). An Overview of Crisis Management in Housing Project. Imperial Journal of Interdisciplinary Research (IJIR), 2(7), pp.886-889. The Effects of Pandemic on Construction Industry in the UK 52

Rahi, S., (2017). Research design and methods: A systematic review of research paradigms, sampling issues and instruments development. International Journal of Economics E Management Sciences, 6(2), pp.1-5.

Sharma, G., (2017). Pros and cons of different sampling techniques. International journal of applied research, 3(7), pp.749-752.

Shekhar, P., Prince, M., Finelli, C., Demonbrun, M. and Waters, C., (2019). Integrating quantitative and qualitative research methods to examine student resistance to active learning. European Journal of Engineering Education, 44(1-2), pp.6-18.

Sherman, W.S. and Harris, R.D., (2018). Crisis? What Crisis? Strategic Crisis Management, and the GM Ignition Switch Crisis. SAM Advanced Management Journal, 83(1), p.41.

Simard, M. and Laberge, D., 2018. Development of a crisis in a project: a process perspective. International Journal of Managing Projects in Business.

Smith, R.D., Keogh-Brown, M.R. and Barnett, T., (2011). Estimating the economic impact of pandemic influenza: an application of the computable general equilibrium model to the UK. Social science $\mathcal{E}$ medicine, 73(2), pp.235-244. 
Srinivasan, N.P. and Nandhini, N., (2016). An Exploratory Study on Factors Governing Crisis Management Implementation in Construction Projects. International Journal of Engineering and Management Research (IJEMR), 6(2), pp.44-47.

Supriadi, L.S.R. and Pheng, L.S., (2018). Business continuity management in construction. Springer Singapore.

Tobi, H. and Kampen, J.K., 2018. Research design: the methodology for interdisciplinary research framework. Quality \& quantity, 52(3), pp.1209-1225. The Effects of Pandemic on Construction Industry in the UK 53

Wisittigars, B. and Siengthai, S., (2019). Crisis leadership competencies: the facility management sector in Thailand. Facilities. 